\title{
New Concept of Hybrid Drive with Multi-Gear Planetary Transmission
}

\author{
J. Plomer \\ Faculty of Transportation Sciences, Czech Technical University, Prague, Czech Republic \\ Corresponding author: Jan.Plomer@seznam.cz
}

DOI: $10.2478 / \mathrm{v} 10158-012-0050-\mathrm{z}$

\begin{abstract}
Paper presents an innovative concept of a hybrid drive with two- or three-gear planetary transmission. The arrangement can be extended by one or two additional clutches. Considering the minimum of two-gear planetary transmission, the combustion engine can work in an optimum efficiency mode, i.e., with low consumption and thus with reduced emissions of pollutants, as well as in modes enabling energy storage. Individual gears of the multifunction transmission, constructed as a system as simple as possible, accommodate various driving demands, e.g., serial or parallel driving modes, or parking blockage.
\end{abstract}

KEY WORDS: Hybrid drive, multi-gear planetary transmission, gear clutches.

\section{INTRODUCTION}

Hybrid drive of motor vehicles is an important step between vehicles with combustion engines, widely used for about a century, and cars with purely electric drives, considered environmentalfriendly and efficient tools for transportation in the future. Mobility of the world population increases, which calls for decrease in total energy consumption and prevention of energy losses in driving systems, e.g., by recuperation.

Nowadays, the ratio of purely electric drives with switched off combustion engine increases significantly for motor vehicles thanks to inventions of new concepts of hybrid drives (e.g., Plesko et al., 2008). A great emphasis is put on reducing the time of running combustion engines to minimum, particularly at short-distance trips in urban areas. The activation of combustion engines is limited to situations requiring high-power or with the lack of energy in the energy storage system, i.e., for the system recharge. Such concepts are known as Plug-InHybrids with an electric plug for external charging of the energy storage system, or, as Range Extender-Hybrids, containing an electric drive which gains energy from a combustion engine connected to an electric motor. The latter drive type enables their flexible functioning, thanks to the fact that the combustion engine can work in both modes - being an electric energy generator and/or a mechanical drive of the motor vehicle. However, concepts of vehicles equipped with only electric motors without a combustion engine are too dependent on the size, capacity and power of electric storage systems, which results in a significant limitation of their usage at the moment.

A new idea (Plomer, 2013), introduced in this paper, is based on a hybrid drive of vehicle concepts driven by one combustion engine and equipped with two electric motors and minimum of one two-gear transmission. The designed solution assumes the transmission is of a planetary design with an annulus, a sun, a planet carrier of several peripheral planet gears and several shifting elements that all together allow for shifting of several gears. 


\section{HYBRID DRIVETRAIN DESIGNS}

Similarly to the Plug-In-Hybrids and Range-Extender-Hybrids, the new concept of hybrid vehicle drives (Plomer, 2013) includes two electric motors and one combustion engine (Figure 1, 3, 4 and 5). On top of that, incorporating a multi-gear planetary transmission into the system allows us to optimize revolutions of the combustion engine. The designed drivetrains contain optionally up to two additional clutches for shifting mechanical gears. The first electric motor of the designed hybrid drive plays a role of a generator of electric energy and the other one of the driving electric motor. The power of individual electric motors may differ. In certain driving modes, functions of both electric motors are interchangeable and can be active in parallel.

\subsection{Hybrid drivetrain with two-gear planetary transmission}

Two electric motors and the planetary transmission are arranged coaxially in the drivetrain as shown in (Figure 1). The input shaft of the transmission is connected with the shaft AN of the combustions engine VM and a rotor of the electric motor EM1, while the rotor of the electric motor EM2 is linked with the output shaft of the planetary transmission. The electric motors EM1 and EM2 are controlled by software of the Energy management EN, based on the required amount of energy. A small energy storage system of only 1-3 kWh capacity forms a part of the Energy management. Two electric motors EM1 and EM2 as well as the energy storage system are designed in such way that the maximum power capability of motor EM2 equals to the sum of power capabilities of the EM1 and the energy storage system. For example, the EM2 can reach the peak power of $30 \mathrm{~kW}$ and the EM1 motor and the energy storage system of $15 \mathrm{~kW}$ each. The combustions engine VM can be of a Diesel type with the power of $30 \mathrm{~kW}$.

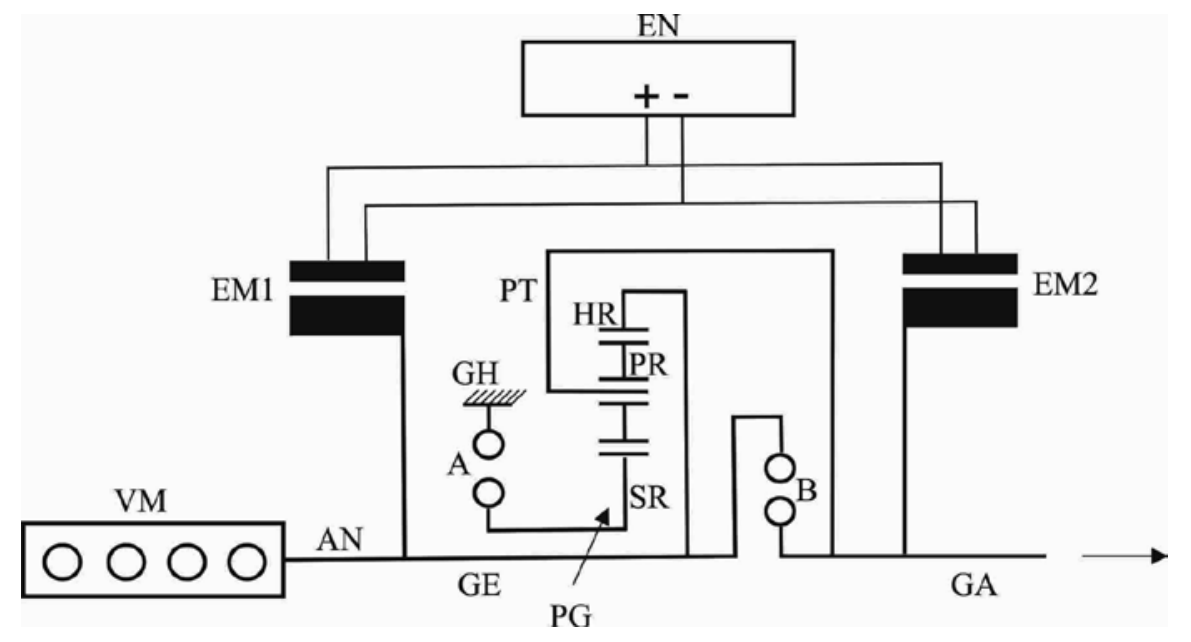

Figure 1: Hybrid drivetrain with two-gear planetary transmission.

The planetary transmission is located in between the electric motors EM1 and EM2. It consists of an annulus HR, a sun SR and a planet carrier PT with peripheral planet gears PR. The planet carrier is under a load of the sun and annulus. The annulus is connected to the input shaft of the transmission and the planet carrier is linked with the output shaft of the transmission. The sun is laid free.

Furthermore, two shifting elements A and B, depicted as gear clutches, are considered in the drivetrain (Figure 1). The sun SR can be fixed to the body of the transmission by clutch A. Clutch B is located in between the annulus and the gear carrier. As a result 
of this arrangement, the planetary transmission can be blocked and consequently the direct power transfer can be achieved by joining the input and output shafts of the transmission.

Gear scheme (Table 1) presents one purely electric "gear" D0-E, two mechanical gears $\mathrm{D} 1$ and D2, backward running $\mathrm{R}$, neutral $\mathrm{N}$ and parking blockage $\mathrm{P}$. The input and output shafts of the transmission are disconnected at "gear" D0-E and therefore, power from the EM1 motor cannot be transferred. The car is driven solely by the second electric motor EM2, directly coupled with the output shaft of the transmission. The required power is controlled by the Energy management in dependence on the actual charging of the energy storage system, course of the ride, driver's wishes or driving mode. The necessary amount of electric energy can be used either solely from the energy storage system without any help of the combustion engine and/or gained from the combustions engine working in the generator mode with the electric motor EM1. A purely electric drive, without activated combustion engine can be realistically used for speeds up to $50 \mathrm{~km} / \mathrm{h}$ and distances up to $10 \mathrm{~km}$.

Table 1: Gear scheme of two-gear planetary transmission.

\begin{tabular}{|c|c|c|c|}
\hline \multirow{2}{*}{ Gear } & \multicolumn{2}{|c|}{ Clutch } & Gear ratio \\
\cline { 2 - 3 } & $\mathrm{A}$ & $\mathrm{B}$ & i \\
\hline $\mathrm{D} 0-\mathrm{E}$ & & - & - \\
\hline $\mathrm{D} 1$ & $\mathrm{x}$ & - & 1.622 \\
\hline $\mathrm{D} 2$ & - & $\mathrm{x}$ & 1.000 \\
\hline $\mathrm{R}$ & - & - & - \\
\hline $\mathrm{N}$ & - & - & - \\
\hline $\mathrm{P}$ & $(\mathrm{x})$ & $\mathrm{x}$ & - \\
\hline
\end{tabular}

(x) optional

Two mechanical gears D1 and D2 are available provided that the input and output shafts of the planetary transmission are connected. Then the annulus represents the input element and the planet carrier the output one. The gear clutch A is closed in the first gear D1 and the sun is stopped. For example, this can result in a gear ratio $\mathrm{i}=1.622$ (Table 1) with the use of gear numbers as follows: the sun 69, the peripheral planet gear 18 and the annulus 111 . The gear clutch $\mathrm{B}$ is closed at the second gear $\mathrm{D} 2$, which leads to the ratio $\mathrm{i}=1.000$. In this case, the planetary transmission rotates as a block. The closing both clutches A and B comes about automatically by actuators depending on the current situation.

The combustion drive can be optionally supported by the electric motors EM1 and EM2, particularly in cases of a sudden demand for increased power of the engine. Thanks to the generator course of the electric motor EM1, a part of the torque of the combustions engine can be stored in the energy storage system assuming the gears D1 and D2 are active. This accumulated energy can be consequently exploited in the electric motor EM2 during the acceleration (Boost function).

The backward running $\mathrm{R}$ of the system is performed by a reverse running of the electric engine EM2. By opening both gear clutches A and B, and deactivation of the electric drive, the car is put into neutral $\mathrm{N}$. Parking blockage $\mathrm{P}$ can be implemented by closing the gear clutch $\mathrm{B}$ and by switching off the combustion engine. The transmission can be additionally blocked by closing the gear clutch A. Short-term torque of electric motor EM2 can be used to unlock the parking blockage.

Figure 2 shows an example of a speed diagram of the combustion engine with the designed planetary transmission. The combustion engine always runs in the optimal operating revolutions and thus with the lowest specific fuel consumption and in the most economic mode. The combustion engine works with the lowest specific consumption in the electric D0-E gear at the speed up to $50 \mathrm{~km} / \mathrm{h}$ under constant revolutions. 
The combustion engine plays an exclusive role of a generator of electric energy in this serial arrangement when using the electric motor EM1. Shifting the first mechanical gear D1 means the combustion engine runs at revolutions determined by the gear ratio. At the speed of $80 \mathrm{~km} / \mathrm{h}$, the car is put in the second mechanical gear D2 automatically. The gear change does not interrupt the power flow.

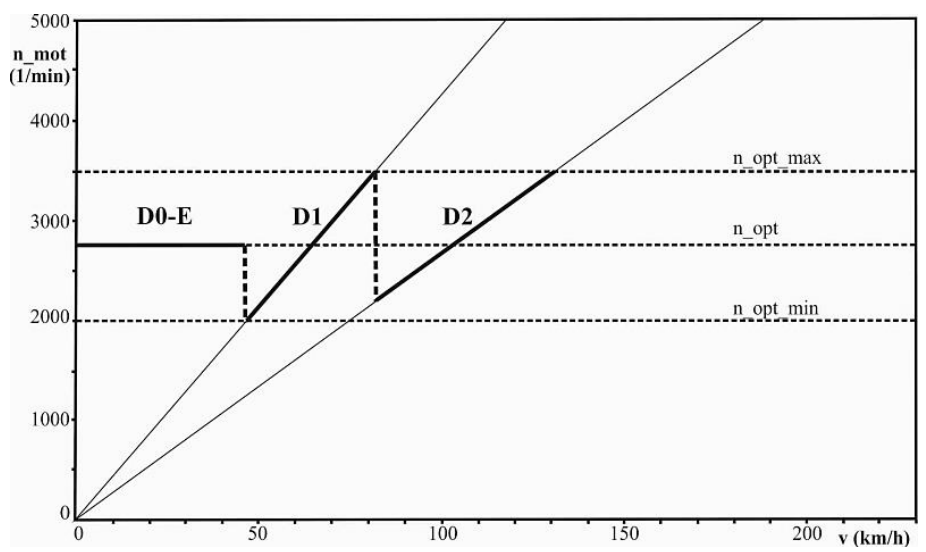

Figure 2: Speed diagram of the new hybrid drive concept.

\subsection{Hybrid drivetrain with three-gear planetary transmission}

Drivetrain scheme in Figure 3 shows another option of a hybrid drive with three mechanical gears. The planetary transmission is extended with an additional mechanical gear D3 and is presented as a reduction gear mechanism. The transmission consists of two annuluses HR1 and HR2 and corresponding planetary gear mechanisms PR1 and PR2. The two planetary gears are coaxially arranged, have a common planet carrier PT, and in pars join peripheral planetary gears PR1 and PR2. The annuluses H1 and H2 can be connected with the input shaft of the transmission by gear clutches B and C. The sun SR, revolving on the output shaft of the transmission and optionally linked with the stable parts of the transmission by gear clutch A, is continuously integrated with the planetary gear mechanism PR2.

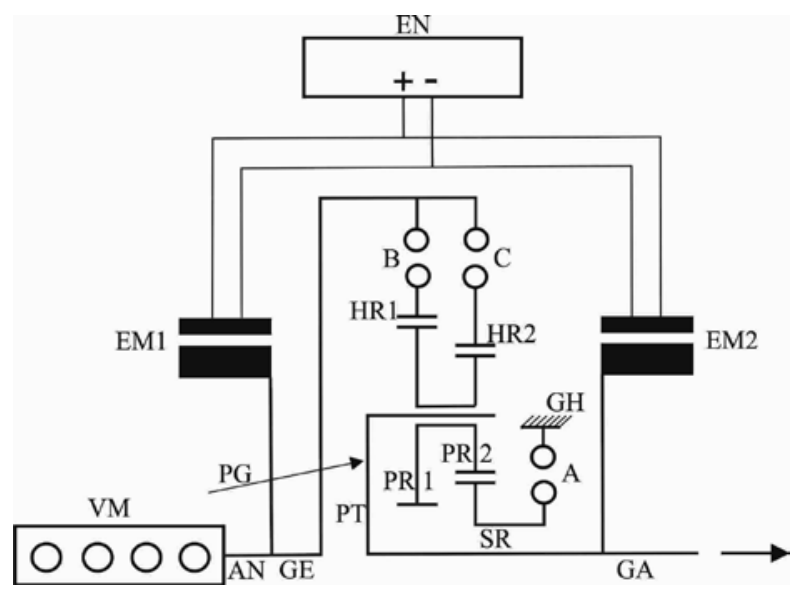

Figure 3: Hybrid drivetrain with three-gear planetary transmission.

Equally to the scheme with the transmission containing two mechanical gears (Table 1), the bottom gear D0-E of the tree-gear mechanical transmission (Table 2) is purely electric one and the car is driven solely by the electric motor EM2. At the gear D1 the connected clutch A stops the sun SR and the gear clutch C links the second planet gear mechanism PR2 to the input 
shaft of the transmission. At the gear D2 the A clutch again stops the sun SR, but in this case, the input shaft of the transmission is linked with the first planet mechanism PR1 by the clutch B. At the gear D3 clutches B and C are joined simultaneously, annuluses of both planet gear mechanisms are connected to the input shaft of the transmission and the sun SR revolves free.

Table 2: Gear scheme of three-gear planetary transmission.

\begin{tabular}{|c|c|c|c|}
\hline \multirow{2}{*}{ Gear } & \multicolumn{3}{|c|}{ Clutch } \\
\cline { 2 - 4 } & A & B & C \\
\hline D0-E & & - & - \\
\hline D1 & $\mathrm{X}$ & - & $\mathrm{X}$ \\
\hline D2 & $\mathrm{X}$ & $\mathrm{x}$ & - \\
\hline D3 & - & $\mathrm{X}$ & $\mathrm{X}$ \\
\hline R & - & - & - \\
\hline N & - & - & - \\
\hline P & $(\mathrm{x})$ & $\mathrm{x}$ & $\mathrm{x}$ \\
\hline
\end{tabular}

\subsection{Hybrid drivetrain with extended clutches}

The designed hybrid drives (Figure 1 and 3) can be extended with a setting-in-motion clutch $\mathrm{K} 0$ located between the combustion engine and the input shaft of the planetary transmission (Figure 4). Then, e.g. a two-gear transmission can be used according to the scheme in Table 3, with the same gear ratios as those presented in Table 1.

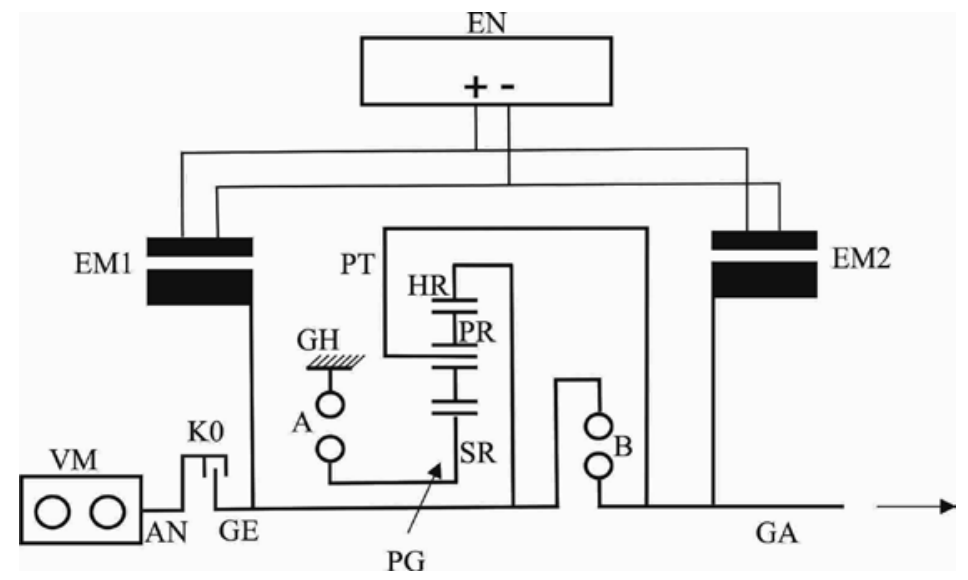

Figure 4: Hybrid drivetrain extended by additional clutch Ko.

Table 3: Gear scheme of two-gear planetary transmission with additional clutch K0.

\begin{tabular}{|c|c|c|c|c|}
\hline \multirow{2}{*}{ Gear } & \multicolumn{3}{|c|}{ Clutch } & Gear ratio \\
\cline { 2 - 4 } & A & B & K0 & i \\
\hline R-E & $(\mathrm{x})$ & - & - & - \\
\hline D0-E & - & - & $\mathrm{x}$ & - \\
\hline D1 & $\mathrm{x}$ & - & $\mathrm{x}$ & 1.622 \\
\hline $\mathrm{D} 2$ & - & $\mathrm{X}$ & $\mathrm{X}$ & 1.000 \\
\hline $\mathrm{R}$ & - & - & $(\mathrm{x})$ & - \\
\hline N & - & - & - & - \\
\hline P & $\mathrm{x}$ & $\mathrm{x}$ & $(\mathrm{x})$ & - \\
\hline
\end{tabular}


Pure electric setting-in-motion of a vehicle, or purely electric ride, is possible, if the settingin-motion clutch $\mathrm{KO}$ is disconnected and the gear clutch $\mathrm{A}$ is closed. In that case, the vehicle is driven solely by the electric engine EM1 because the combustion engine VM is disconnected completely from the drive. On the other hand, the purely electric setting-inmotion and/or ride can be controlled by the electric motor EM2 if the gear clutch B is disconnected. Two mechanical gears are available for the motor EM1 in the planetary transmission. Evenly, the backward running $\mathrm{R}$ is performed by two gears of the motor EM1 if the clutch $\mathrm{K} 0$ is opened. If the clutch $\mathrm{K} 0$ is closed and the gear clutch $\mathrm{B}$ is opened, the backward running is possible only with the help of the electric motor EM2. Closing gear clutches A and B simultaneously results in parking blockage P. In this case, the setting-inmotion clutch $\mathrm{K} 0$ can also be closed. The combustion engine can support the drive if any sudden power increase is required, e.g., during the engine start uphill.

A drivetrain presented in Figure 5 is extended with another clutch K1, in comparison with the scheme in Figure 4. The coaxially located clutch K1 in between the input shaft and the annulus HR can be of a gear type. The rotor of the electric motor EM1 is placed on the input shaft of the transmission in between two clutches $\mathrm{K} 0$ and $\mathrm{K} 1$.

If a vehicle with the hybrid drive designed in Figure 5 stops uphill, the parking blockage $\mathrm{P}$ is activated by the closing clutches $\mathrm{A}$ and $\mathrm{B}$. However, what may happen is that there is not enough amount of energy in the storage system to release the parking blockage $\mathrm{P}$ by electric motors EM1 and EM2 and to set the car in motion. In such case, the clutch K0 disconnects and the combustions engine is started up by the electric motor EM1, while the clutch $\mathrm{K} 1$ is closed. The starting mode requires only a small amount of energy in comparison with the amount of energy needed to release the parking blockage. When the car is stopped in a steep uphill, a high torque is required to start the car moving. Therefore, after a start of the combustion engine with disconnected setting-in-motion clutch $\mathrm{K} 0$ and closed $\mathrm{K} 1$ clutch, the clutch $\mathrm{K} 0$ connects again under the load and the torque of the combustions engine is transferred into the planetary transmission. Consequently, the gear clutch B disconnects and the torque transfers via the closed clutch A on the output shaft of the transmission. The significant advantage of this hybrid drive (Figure 5) is based on a possibility of energy storage. Under the disconnected clutch $\mathrm{K} 1$ and connected clutch K0, the generated energy can be stored in the energy storage system, even if the planetary transmission is blocked and the parking blockage P activated. In such case, the electric motor EM1 works as a generator of electric energy. An example of the gear ratios presented in Table 4 for the hybrid concept in Figure 5 corresponds to the example numbers of gears given in Table 1.

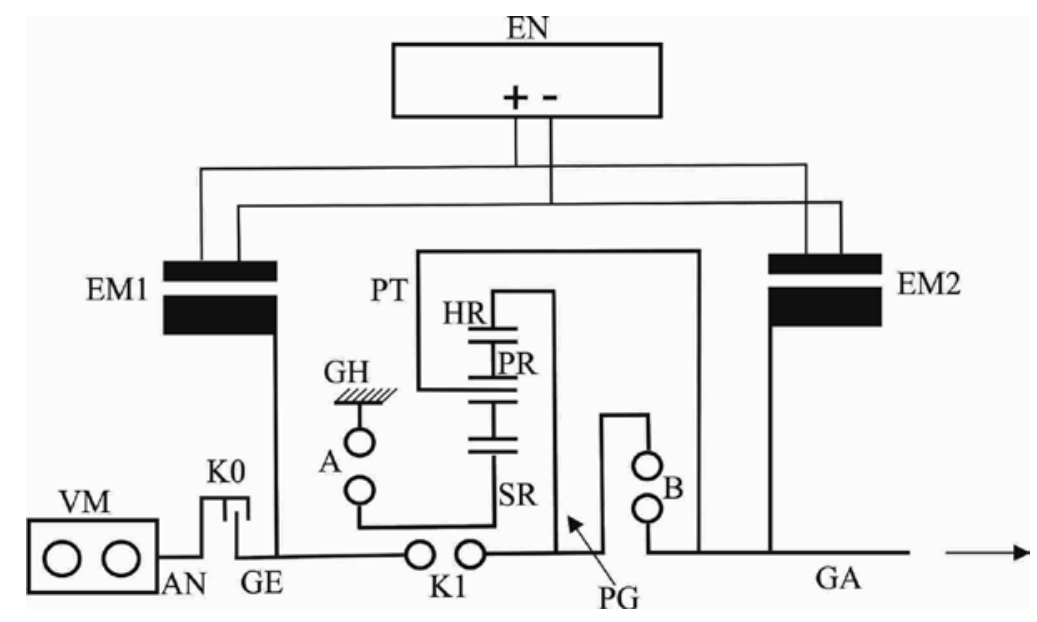

Figure 5: Hybrid drivetrain extended by two additional clutches. 
Table 4: Gear scheme of two-gear planetary transmission with extended clutches.

\begin{tabular}{|c|c|c|c|c|c|}
\hline \multirow[t]{2}{*}{ Gear } & \multicolumn{4}{|c|}{ Clutch } & \multirow{2}{*}{$\begin{array}{c}\text { Gear ratio } \\
\text { i } \\
\end{array}$} \\
\hline & A & B & K0 & K1 & \\
\hline R-E & $(\mathrm{x})$ & - & - & $\mathrm{X}$ & - \\
\hline D0-E & - & - & $\mathrm{X}$ & $\mathrm{X}$ & - \\
\hline D1 & $\mathrm{X}$ & - & $\mathrm{X}$ & $\mathrm{X}$ & 1.622 \\
\hline$\overline{\mathrm{D} 2}$ & - & $\mathrm{X}$ & $\mathrm{X}$ & $\mathrm{X}$ & 1.000 \\
\hline $\mathrm{R}$ & - & - & $(\mathrm{x})$ & $\mathrm{X}$ & - \\
\hline $\mathrm{N}$ & - & - & - & $\mathrm{x}$ & - \\
\hline $\mathrm{P}$ & $\mathrm{X}$ & $\mathrm{X}$ & $(\mathrm{x})$ & $(\mathrm{x})$ & - \\
\hline
\end{tabular}

\section{INNOVATIVE CONCEPT IN LIGHT OF PREVIOUS PATENTS AND ITS ADVANTAGES}

The designed concept with two basic variants of the innovative hybrid drives, potentially extended by additional clutches (patent DE 102011085149 A1, released on 25 April, 2013; Plomer, 2013) represents an important step in hybrid drive development (Horčík, 2013).

Patent DE 69732387 T2 (Ibaraki et al., 2006) of a hybrid drive for a vehicle contains similar basic building elements - one combustion engine, two electric motors and a simple planetary transmission with a sun, a planet carrier and an annulus, but the arrangement of the building elements and the system functioning differ. The two electric engines, the planetary transmission as well as the input and output shafts are arranged coaxially, i.e., in a single axis. The planet carrier is connected to the combustion engine via the input shaft and the annulus is linked to the output shaft of the transmission. The rotor of one of the electric motors is connected to the output shaft of the transmission whereas the rotor of the second electric motor is joined with the sun. The planetary transmission only acts as a dividing element to mechanical torque-split of the combustion engine.

Similar building elements form the hybrid drivetrain of Patent DE 102008053505 A1 (Hinrichsen \& Hofmann, 2010). One of the electric motors is connected with the combustion engine and works as a generator. A clutch is in between the generator and the transmission. The one-gear transmission has a fixed gear ratio which can correspond to, e.g., the highest gear of a common transmission. Instead of two electric motors, or, in addition to them, inwheel electric motors can be designed (e.g., Kovanda \& Kobrle, 2012). An energy storage system, connected to electric motors is also available. The system allows six different driving modes: (1) purely electric drive - applicable in the case of low demands on power, e.g., in a city; (2) mode of recuperation - in which the second electric motor works as a generator of electric energy and braking energy is transferred into electric one, stored afterwards in the energy storage system; (3) serial ride and boost mode - electric energy generated by the combustion engine and in generator are available and usually used for driving car at low speeds; the drive works as a serial hybrid and can use the energy from the energy boost system; (4) serial hybrid driving mode and charging - a part of energy is used for driving and the remaining part is stored in the energy storage system; (5) parallel driving mode and boost - the combustion engine can be supported by the electric motor powered from the energy storage system and the power is mechanically transported by one fixed gear; (6) parallel ride and charging - the combustion engine works as a source of energy to run the motor vehicle. The system is rather complicated and expensive. 
Therefore, the fundamental task for the new invention (DE 102011085149 A1, Plomer, 2013) was to design a hybrid drive which is efficient in running and economical in its production. The designed new arrangement of the building elements and, particularly, the incorporation of the two- or three-gear planetary transmissions into the hybrid drivetrain fulfilled the task and put forward the hybrid drive ideas.

One of the advantages of the hybrid drive according to the presented invention is in its independence on a size of the energy storage system used in the vehicle. Thanks to that, the energy storage system of a capacity of several kWh can be smaller, lighter and thus also cheaper in comparison with that of vehicles using exclusively electric drive, and/or, of the Plug-In- and Range-Extender-concepts. Moreover, no independent heating needs to be installed into the designed hybrids, as residual heat from the combustion engine can be used in the system.

One or two setting-in-motion clutches, incorporated in the innovative drivetrains, are optional, but not necessary. The reason is that even the basic concept includes an electric setting-in-motion function (D0-E, Tables 1-3). In the same way, no separate elements for the backward vehicle running are needed, because the reverse running of the electric motor can be employed for that. The so-called "START-STOP" function of the combustion engine is realized with the use of the first electric engine and thus no extra starter is required.

Production costs of the proposed hybrid decrease further thanks to the fact that parking blockage can be realized directly by blocking of the planetary transmission and thus no additional elements for parking blockage of automatic transmissions are needed. One of the electric motors can be used to release the parking blockage and to open the clutches.

The hybrid drive design is effective in urban traffic, or at low velocities in exclusively electric mode, and also for long-distance trips at higher speeds out of town, when the combustion engine is switched on to generate electric energy for the electric motor EM1 or drives directly the vehicle wheels, if required.

In contrast to the Plug-In-Hybrid and Range-Extender-Hybrid concepts, where the transmission plays a role of only a divider of driving force between the combustion engine and electric motor, the multi-gear planetary transmission included in the new concept enables to optimize operational revolutions of combustion engine in dependence on vehicle speed in such way that the combustion engine runs in optimal mode with a low fuel consumption and high efficiency.

In the simpler version (Figure 1), the transmission is designed as a simple planetary gear mechanism with one sun, a planet carrier with several peripheral gears and two shifting elements allowing two gears to be shifted. The planetary transmission is designed with negative basic gear ratio. In contrast to the transmissions with positive gear ratios, the designed arrangement with the negative ratio is simpler and exhibits greater efficiency of the transmission by having fewer number of gears engaged.

The designed arrangements enable a smooth start-up of vehicle by the electric motor EM2. They have at least two gears in the planetary transmission, one of which is 'direct'; furthermore, they have electric backward running and, last but not least, possess ability to block the transmission. The significance of exclusively electric mode is decisive in urban traffic, due to repeated startups of vehicles, or stopping and accelerating in traffic jams. The utilization of exclusively electric mode depends on the amount of energy stored in the energy storage system.

The designed system also enables the so-called BOOST function in the case of increased dynamics of the vehicle. Then, both electric motors can be used simultaneously to drive the vehicle, e.g., for acceleration. Thanks to that, a car will exhibit 
very good ride dynamics, even in case that a relatively weak, and thus cheap and efficient, combustion engine is built in the vehicle.

Both shifting elements of the planetary transmission can be designed with the aim of achieving the highest speed of the vehicle and overdrive. Then the combustion engine constantly operates in the optimal mode and is adjusted for requirements both on maximum power and on economy. The two gear units of the planetary transmission (A and B, Figure 1 and 3) can be made as gear clutches without any synchronization. The torque of the two electric motors ensures the shifting is realized without a break of power flow, which is important and desirable for ride comfort.

In the frame of extensions of combustion engine modes in hybrid drives, the transmission can be designed as a three-gear planetary transmission as well as a reduction transmission with two annuluses, one sun and one planet carrier with several double peripheral planet gears. This arrangement provides a smooth start of a vehicle, three gears in the planetary transmission, one electric reverse running and blockage of the transmission.

Implementing additional clutch (K0, Figure 4) in between the combustion engine and the input shaft of the transmission represents an additional extension in electric motor functions allowing for a possibility of choosing various connections of these elements. In order to fulfill the requirements for an extension of the hybrid drive functionality, one more additional clutch (K1, Figure 5) can be added into the drivetrain. A new feature brought by this version consists in an axial location of the rotor of electric engine EM1 between the K0 and K1 clutches. Since the rotor is connected to the input shaft of the transmission, the energy from the combustion engine, generated by the EM1, can be stored in the energy storage system, supposing that clutch $\mathrm{K} 0$ is closed and $\mathrm{K} 1$ is opened. This kind of charging of the energy storage system can be executed even if the vehicle is stopped and the parking blockage is activated.

Storing of any kind of energy in systems becomes a challenge for new extensions of hybrid drive concepts. Modern technologies tend to produce flywheels meeting demands on recovering vehicle kinetic energy, which would otherwise be lost, as heat during breaking (e.g., First \& Plomer, 2010; Plomer, 2010; 2011; Yang, 2012).

\section{CONCLUSION}

The new concept of a hybrid drive with two- or three-gear planetary transmission, optionally extended by one or two additional clutches, guarantees a low-cost combustion engine of the system working in the optimum efficiency mode, with sustainable fuel consumption and reduced emissions of pollutants. The multi-gear transmission of the system allows various driving functions and thus additional specific elements are not needed any more. Therefore, the invented hybrid drivetrains represent a promising environmental and economic improvement in constructing vehicle drives for the future.

\section{ACKNOWLEDGEMENT}

The author appreciates discussions with gear specialists in the ZF Friedrichshafen and with Ing. J. First from the Faculty of Transportation of the Czech Technical University. 


\section{REFERENCES}

First, J., Plomer, J., 2010. Accumulation of energy in transportation. In Elektromobilita $v$ silnični dopravě a 21. století [Proceedings of the $10^{\text {th }}$ international conference of the Faculty of Transportation of the Czech Technical University], Prague, April 2010, pp. 7-13. (in Czech)

Hinrichsen, U., Hofmann, L., 2010. Verfahren zur Steuerung eines Hybridantriebsstrangs eines Kraftfahrzeuges [online].Volkswagen AG [DE]. Patent DE102008053505A1[cited 2014-01-23]. Retrieved from: https://depatisnet.dpma.de/DepatisNet/depatisnet?action= bibdat\&docid=DE102008053505A1

Horčík, J., 2013. Český konstruktér si zaregistroval patent na unikátní hybridní pohon. Hybrid.cz [online]. [cited 2014-01-24]. ISSN 1802-5323. Retrieved from: http://www.hybrid.cz/cesky-konstrukter-si-zaregistroval-patent-na-unikatni-hybridni-pohon (in Czech)

Ibaraki, R., Matsui, H., Morisawa, K., Nagano, S., 2006. Hybridantrieb mit einem vom Stator eines Motors/Generators umgebenen Planetengetriebe [online]. TOYOTA Motor Co LTD [JP]. Patent DE69732387T2 [cited 2014-01-23]. Retrieved from: https://depatisnet.dpma.de/DepatisNet/depatisnet?action=bibdat\&docid=DE000069732387T2

Kovanda, J., Kobrle, P., 2012. Selected problems of electric vehicle dynamics. Transaction on Transport Science, 5 (3), pp. 137-142. ISSN 1802-971X.

Plesko, H., Biela, J., Luomi, J., Kolar, J.W., 2008. Novel concepts for integrating the electric drive and auxiliary DC-DC converter for hybrid vehicles. IEEE Transactions on Power Electronics, 23 (6), pp. 3025-3034. ISSN 0885-8993.

Plomer, J., 2010. Setrvačník, inovativní řešení pro hybridní a elektrická vozidla, 1. díl. Hybrid.cz [online]. [cited 2014-01-24]. ISSN 1802-5323. Retrieved from: http://www.hybrid.cz/clanky/setrvacnik-inovativni-reseni-pro-hybridni-elektricka-vozidla-1-dil (in Czech)

Plomer, J., 2011. Setrvačník, inovativní řešení pro hybridní a elektrická vozidla, 2. díl. Hybrid.cz [online]. [cited 2014-01-24]. Retrieved from: http://www.hybrid.cz/clanky/setrvacnik-inovativni-reseni-pro-hybridni-elektricka-vozidla-2-dil (in Czech).

Plomer, J., 2013. Hybridantrieb für ein Kraftfahrzeug [online]. ZF Friedrichshafen AG [DE]. Patent DE102011085149A1 [cited 2014-01-23]. Retrieved from: https://depatisnet.dpma.de/DepatisNet/depatisnet?action=bibdat\&docid=DE102011085149A1

Yang, X., 2012. Experimental research of a flywheel hybrid vehicle. In Chen, W.Z., Dai, P., Chen., Y., L.,Wang, Q.T., Jiang., Z. (eds.). Advanced mechanical design, PTS1-3, Advanced Material Research, (479-481), pp. 439-442. doi: 10.4028/www.scientific.net/AMR.479-481.439. 